\title{
Application of clockwise modularized laparoscopic lymphadenectomy in the suprapancreatic area, a propensity score matching study and comparison with open gastrectomy
}

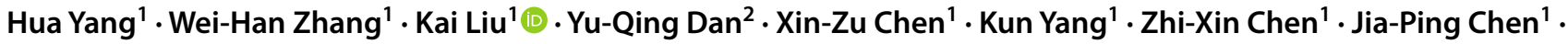 \\ Zong-Guang Zhou ${ }^{3}$. Jian-Kun Hu ${ }^{1}$
}

Received: 16 May 2020 / Accepted: 29 September 2020 / Published online: 8 October 2020

(c) The Author(s) 2020

\begin{abstract}
Background Suprapancreatic lymphadenectomy is the essence of D2 radical gastric cancer surgery. The present study aimed to describe clockwise modularized laparoscopic lymphadenectomy in the suprapancreatic area.

Methods The data from gastric cancer patients who underwent surgical treatment from September 2016 to December 2018 were collected. Patients were divided into clockwise modularized lymphadenectomy (CML) and traditional open gastrectomy (OG) groups according to the surgical treatment strategy. The propensity score matching method was utilized to balance the baseline characteristics between the two groups.

Results Finally, 551 gastric cancer patients were included in the present study. Following propensity score matching, 106 pairs of patients in the CML group and OG group were included in the final analysis. The CML group had more total examined lymph nodes (36, IQR 28-44.74 vs. 29, IQR 29-39.5, $p=0.002)$ and no. 9 station nodes (2, IQR 1-5 vs. 2, IQR 1-3, $p=0.007$ ) than the OG group. There was less intraoperative blood loss (30, IQR $20-80 \mathrm{ml}$ vs. 80, IQR 50-80 ml, $p<0.001$ ) and a longer surgical duration (262.5 $\mathrm{min}$, IQR $220-303.25 \mathrm{~min}$ vs. 232 , IQR $220-255 \mathrm{~min}, p<0.001$ ) in the CML group than in the OG group. The incidence of postoperative complications $(19.8 \%$ vs. $16.0 \%, p=0.591)$ and postoperative hospital stay (8, IQR 7-9 days vs. 8, IQR 7-9 days, $p=0.452$ ) were comparable between the CML and OG groups.

Conclusion Laparoscopic lymphadenectomy for gastric cancer surgery is technically demanding. Clockwise modularized laparoscopic lymphadenectomy in the suprapancreatic area can attain similar effects as traditional open surgery and without an increase in postoperative adverse events.
\end{abstract}

Keywords Gastric cancer · Laparoscopy · Lymphadenectomy · Pancreas

$\begin{array}{ll}\text { Abbreviations } \\ \text { CML } & \text { Clockwise modularized lymphadenectomy } \\ \text { OG } & \text { Open gastrectomy } \\ \text { RCTs } & \text { Randomized control trials }\end{array}$

Hua Yang, Wei-Han Zhang have contributed equally to this work.

Electronic supplementary material The online version of this article (https://doi.org/10.1007/s00464-020-08070-w) contains supplementary material, which is available to authorized users.

Jian-Kun $\mathrm{Hu}$

hujkwch@126.com

1 State Key Laboratory of Biotherapy, Department of Gastrointestinal Surgery and Laboratory of Gastric Cancer, Collaborative Innovation Center for Biotherapy, West China Hospital, Sichuan University, No. 37 Guo Xue Xiang Street, Chengdu, Sichuan Province, China
CLASS Chinese Laparoscopic Gastrointestinal Surgery Study

SGCPR Surgical Gastric Cancer Patient Registry

BMI Body mass index

The use of laparoscopic gastrectomy for gastric cancer patients has received increasing attention in recent years [1]. The short-term surgical safety and long-term oncological

2 West China School of Medicine, Sichuan University, Chengdu, China

3 State Key Laboratory of Biotherapy, Department of Gastrointestinal Surgery and Laboratory of Digestive Surgery, Collaborative Innovation Center for Biotherapy, West China Hospital, Sichuan University, Chengdu, China 
safety of laparoscopic gastric cancer surgery have been shown to be equivalent to those of traditional open surgery [1-3]. For advanced stage cancers, the short-term results from both the KLASS-02-RCT and JLSSG0901 trials confirm the noninferiority of laparoscopic gastrectomy to open gastrectomy [4, 5]. A recently reported study from the Chinese Laparoscopic Gastrointestinal Surgery Study (CLASS) group, the CLASS-01 trial, indicated that laparoscopic distal gastrectomy had comparable postoperative short-term adverse events and 3-year disease-free survival outcomes to open distal gastrectomy for locally advanced-stage gastric cancers $[6,7]$. Therefore, the surgical and oncology safety of laparoscopic surgery for advanced-stage gastric cancer patients have been preliminarily verified.

Oncological safety is essential in surgical treatments of advanced gastric cancers. Several variables, such as tumor stage, genetic characteristics, and treatment strategy, can influence the survival outcomes of gastric cancer patients [8-10]. Given the limited operating space and lack of stereovision and haptic feedback, complete dissection of the regional lymph nodes is technically demanding in laparoscopic surgery. Laparoscopic lymphadenectomy increases the requirements for cooperation between the operator and assistants over those of traditional open gastrectomy. To facilitate and achieve thorough lymph node dissection, we established clockwise modularized laparoscopic lymphadenectomy strategies in a previous study [11]. However, the technical requirements of laparoscopic gastric cancer lymphadenectomy are even higher in the suprapancreatic area due to the deep anatomical location and variability of the vasculature this area. Meanwhile, achieving thorough lymphadenectomy in the suprapancreatic area without increasing perioperative complications is an essential demand of laparoscopic surgery for locally advanced gastric cancers. Therefore, we asked whether clockwise modularized laparoscopic lymphadenectomy could achieve the same effect as open surgery in suprapancreatic lymphadenectomy.

In the present study, we will present the details about the procedural demands and technical skills of lymphadenectomy in the suprapancreatic area in the clockwise modularized laparoscopic lymphadenectomy model and compare the clinical effect of these procedures with open gastrectomy in the same period by propensity score matching.

\section{Methods and materials}

\section{Patients}

The clinicopathological parameters of gastric cancer patients were retrieved from the database of the Surgical Gastric Cancer Patient Registry (SGCPR) in West China Hospital with the registration number WCH-SGCPR-2019-03 [12].
The use of this database in clinical studies or translational medicine research was approved by the Biomedical Ethical Committee of the West China Hospital, Sichuan University, China (No. 2014-215). Informed consent was obtained from the patients or their guardians. Patient records were anonymized and deidentified before analysis.

From September 2016, our study group summarized the previous experience in laparoscopic surgery and established a standard method for performing clockwise modularized lymphadenectomy to facilitate laparoscopic surgery and promote thorough lymphadenectomy [11]. In this study, we collected gastric cancer patients from September 2016 to December 2018 who underwent radical gastrectomy from the SGCPR database. Patients who had preoperative chemotherapy, preoperative radiotherapy, or distant metastasis were excluded from the present study. Finally, according to the surgical treatment strategy, patients were assigned into a clockwise modularized laparoscopic (CML) group or an open gastrectomy (OG) group (Fig. 1).

\section{Clinicopathological characteristics}

The following clinicopathological characteristics were assessed between the CML and OG groups. General characteristics, such as age (years), sex (male or female), body mass index (BMI) $\left(\mathrm{kg} / \mathrm{m}^{2}\right)$, tumor size $(\mathrm{cm})$, tumor location, macroscopic type, resection types, and tumor stages, were used to estimate the baseline characteristics of the two groups. The operation-related outcomes, such as operation time ( $\mathrm{min}$ ), blood loss ( $\mathrm{ml}$ ), numbers of examined and metastatic lymph nodes (total, no. 7, no. 8a, no. 9, and no. 11p stations), postoperative hospital stay (days) and postoperative 30-day complications, were compared between the two groups.

Pathological examination was conducted by pathologists from the Department of Pathology, West China Hospital, Sichuan University according to the TNM Classification of Malignant Tumors, eighth edition, from the Union for International Cancer Control [13, 14]. Postoperative 30-day complications were defined as the complication incidence during the first 30 days of the postoperative period or complications occurring during the same hospitalization. The severity of postoperative complications was classified according to the Clavien-Dindo system [15].

\section{Surgical treatment}

All patients underwent surgical treatment with radical intention in the Department of Gastrointestinal Surgery, West China Hospital, Sichuan University. The principles of the surgical treatment were based on the Japanese Gastric Cancer Treatment Guidelines [16]. Regardless of the use of either laparoscopic or open surgery, intraoperative frozen 
Fig. 1 Flow chart of patient selection

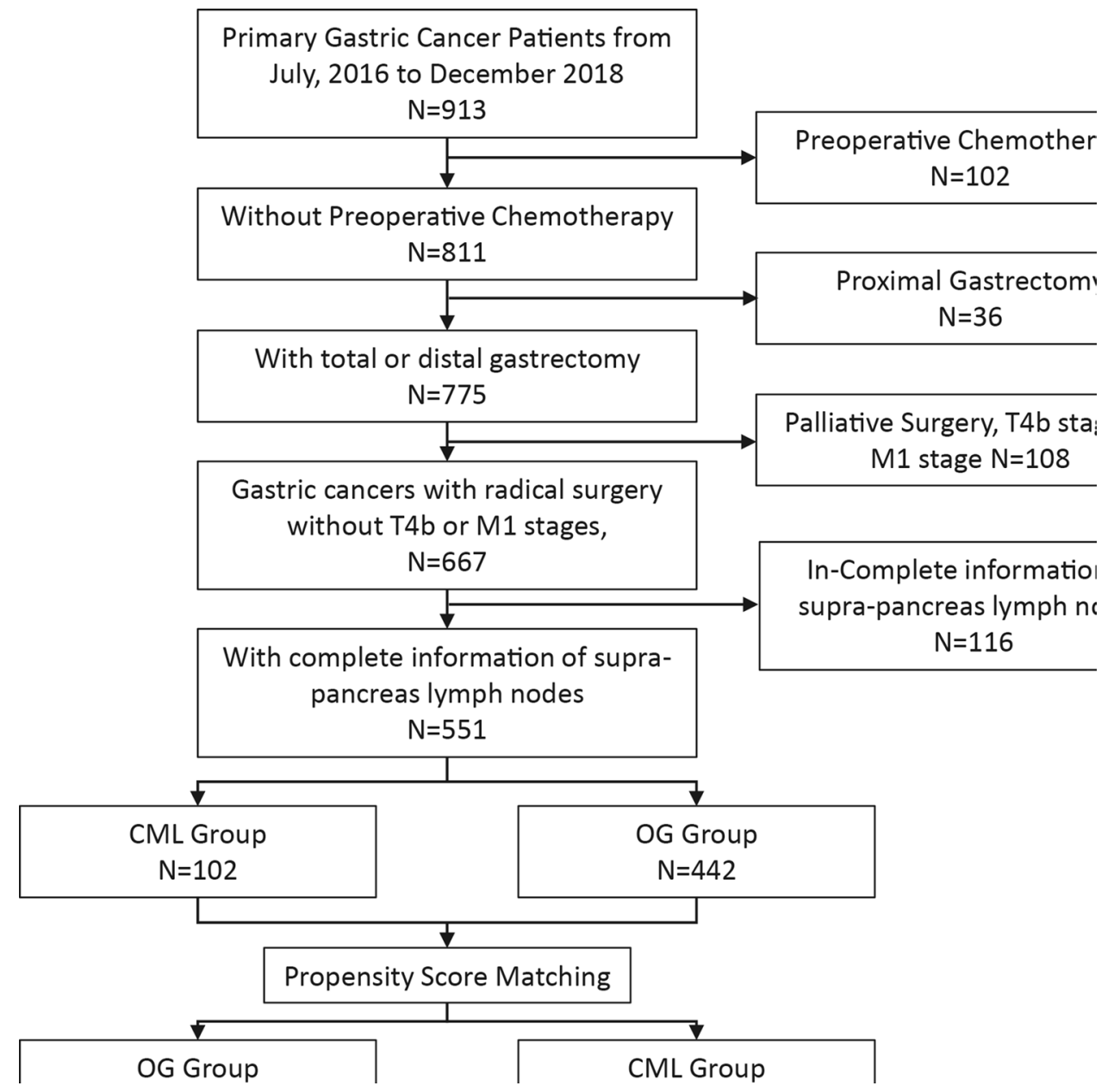

section examinations were routinely conducted to secure the safety of the resection margins. Early-stage gastric cancer patients were recommended to undergo laparoscopic surgery. The surgical indications of laparoscopic gastrectomy for locally advanced cancers were referred to the inclusion and exclusion criteria of the CLASS serious trials [6, 7 , 17]. In particular, the use of laparoscopic gastrectomy or open gastrectomy for patients with advanced tumor stages were based on full communication between the surgeons and patients under the instructions of the Japanese Gastric Cancer Treatment Guidelines [16].

The detailed surgical procedures of clockwise modularized laparoscopic surgery were described in our previous study [11]. The core techniques of the procedure in the suprapancreatic area involve: (1) the nonpressed pancreas technique, (2) the overlook view technique, (3) the layer-bylayer reciprocal dissection procedure and (4) the application of pulling adventitia tissue skills. Details of the surgical procedures of clockwise modularized suprapancreatic lymphadenectomy are presented in Video 1.

Specifically, we emphasize that the assistant should outwardly rotate the upper edge of the pancreas rather than directly deep press it (Fig. 2), and the laparoscope should look down on the suprapancreatic area by adjusting it to approximately $30^{\circ}$ to acquire a similar view as traditional open surgery (Fig. 3). The application of these two skills was aimed at facilitating and securing the safety of suprapancreatic lymphadenectomy. The overlook view allows a clearer observation of the tissues in the back of the pancreas and reduces the possibility of accidental injury. The adoption of the nonpressed pancreas technique reduces direct damage to the pancreas from the laparoscopic instruments. The adoption of these skills can completely expose the spleen vein and portal vein, prevent injury to these vessels, and attain thorough lymph node dissection in the suprapancreatic area (Fig. 4).

\section{Statistical analysis}

All statistical analyses were conducted with R Software Version 3.6.0 (https://www.R-project.org), including the "nonrandom" and "MatchIt" packages. Continuous variables with a normal distribution are presented as the means and standard deviations, and categorical variables are expressed 
Fig. 2 Illustration of the "nonpressed pancreas" technique (A Nonpressed pancreas, B Direct pressure on the pancreas)
Fig. 3 Illustration of the "overlook view" technique

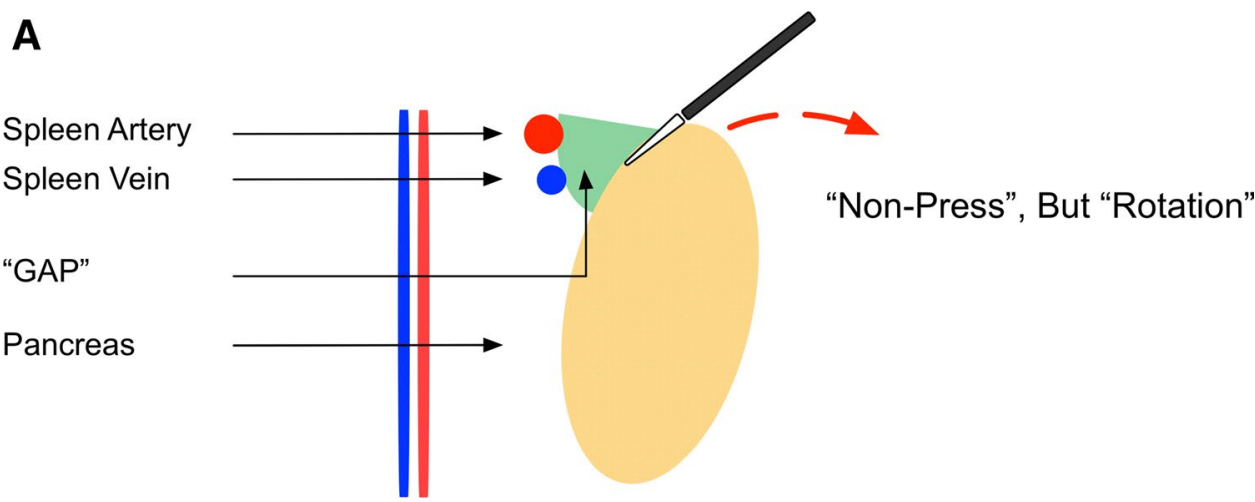

B
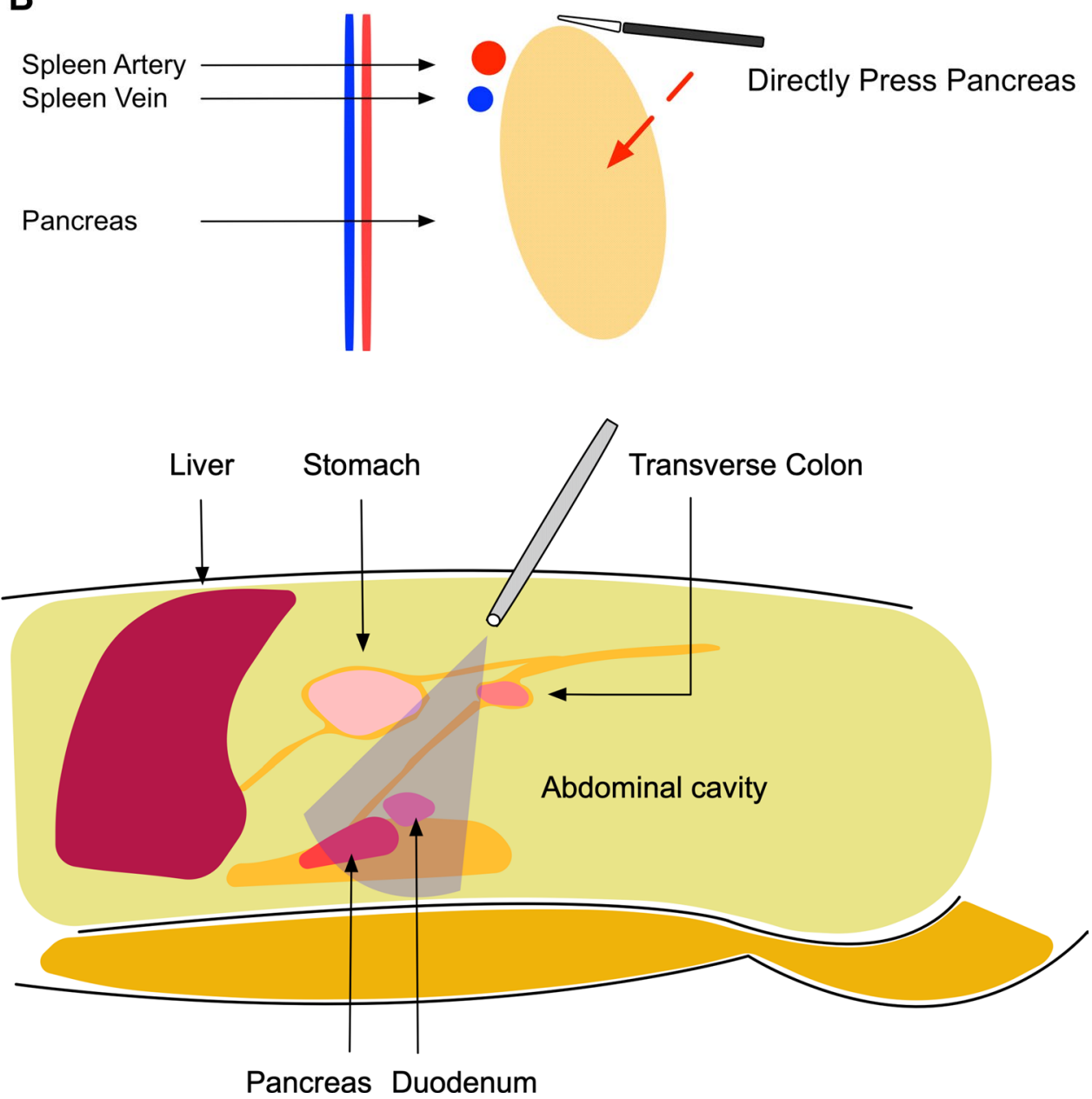

as numbers (\%). Medians and interquantile ranges (IQRs, p25-p75) were used to present continuous variables with abnormal distributions. The Mann-Whitney U test was utilized to analyze continuous variables and ordinal categorical variables, whereas the chi-square test was used for unordered categorical variables. A $P$ value $<0.05$ (2-sided) was defined as statistically significant. The propensity score (PS) was computed using a logistic regression model that included baseline characteristics (age, sex, tumor location, resection type, tumor size, $\mathrm{T}$ stages, and $\mathrm{N}$ stages) to balance the covariates between the CML and OG groups. Propensity score matching pairs were identified without replacement using a 1:1 nearest neighbor matching algorithm with caliper width determined by the recommendation $(0.05$ of the standard deviation of the logit) [18]. The balance of covariates between the groups was assessed by the standardized mean difference (SMD) before and after the matching procedures. An SMD $<0.1$ indicated balance in the covariate 

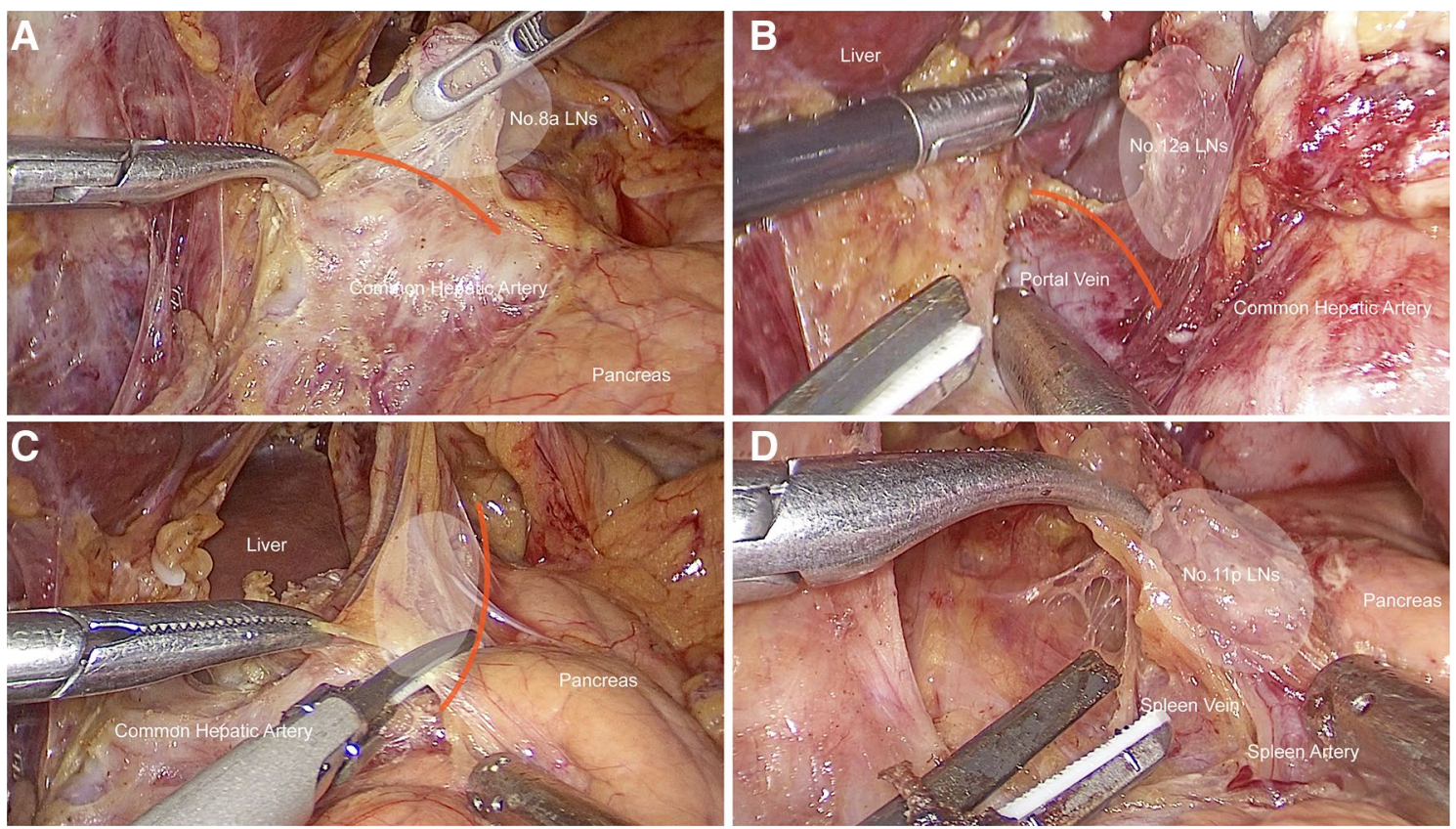

Fig. 4 Intraoperative view of clockwise modularized laparoscopic suprapancreatic lymphadenectomy (A Right side of the suprapancreatic area (No. 8a LNs); B Right side of the suprapancreatic area (No.

12a LNs); C Left side of the suprapancreatic area (No. 7/11p LNs); D Left side of the suprapancreatic area (No. 11p LNs)

between the two groups [19]. After the PS matching procedure, 106 matched pairs were generated with comparable characteristics.

\section{Results}

\section{Clinicopathological characteristics}

Clinical information from 551 gastric cancer patients who underwent radical surgical treatment was retrieved in the present study (Fig. 1). There were 109 patients in the CML group and 442 patients in the OG group. General clinicopathological characteristics are presented in Table 1. Before propensity score matching, five covariates (age, tumor size, tumor location, resection type, $\mathrm{pT}$ stage, and $\mathrm{pN}$ stage) were unbalanced $(p<0.05$ or SMD $>0.1)$. After 1:1 PS matching, 106 matched pairs of patients were obtained with relatively balanced baseline characteristics between the two groups. The standardized differences and distributions of those characteristics before and after matching are presented in Fig. 5 .

\section{Clinical outcomes}

The clinical outcomes were compared between the CML and OG groups, which included operation-related parameters (Table 2). In the after PS-matching cohort, although the CML group had a longer surgical duration than the

OG group (262.5, IQR 220-303.25 min vs. 232, IQR 220-255 min, $p<0.001$ ), it had less intraoperative blood loss than the OG group (30, IQR $20-80 \mathrm{ml}$ vs. 80 , IQR $50-80 \mathrm{ml}, p<0.001)$. The CML group had more total examined lymph nodes (36, IQR 28-44.74 vs. 29, IQR 29-39.5, $p=0.002$ ), whereas there was no difference in the number of total metastatic lymph nodes (1, IQR $0-3$ vs. 0, IQR $0-3.75$, $p=0.965$ ) between the two groups. In addition, there were more examined lymph nodes in the no. 9 station of the CML group than in the OG group (2, IQR 1-5 vs. 2, IQR 1-3, $p=0.007)$.

\section{Postoperative outcomes}

The postoperative-related outcomes compared between the two groups included postoperative hospital stays (days) and postoperative 30-day complications (Table 3). Interestingly, the CML group had a shorter length of postoperative hospital stay than the OG group in the before PS-matching cohort (8, IQR 7-9 days vs. 9, IQR 8-11 days, $p<0.001$ ), and there was no significant difference between the two groups in the after PS-matching cohort (8, IQR 7-9 days vs. 8, IQR 7-9 days, $p=0.452$ ). This may be due to the open gastrectomy group having more advanced tumor stage patients than the CML group in the before propensity score matching cohort. In addition, the CML group had comparable postoperative 30-day complications to the OG group in the after propensity score matching cohort (19.8\% vs. $16.0 \%$, 
Table 1 The clinicopathological characteristics between the clockwise modularized laparoscopic group and open gastrectomy group in before and after propensity scoring matching cohort

\begin{tabular}{|c|c|c|c|c|c|c|c|c|c|}
\hline \multirow[t]{3}{*}{ Characteristics } & & \multicolumn{4}{|c|}{ Before Matching $(N=551)$} & \multicolumn{4}{|c|}{ After Matching $(N=212)$} \\
\hline & & \multirow{2}{*}{$\begin{array}{l}\text { CML Group } \\
N=109(\%)\end{array}$} & \multirow{2}{*}{$\begin{array}{l}\text { OG Group } \\
N=442(\%)\end{array}$} & \multirow[t]{2}{*}{$P$ value } & \multirow[t]{2}{*}{ SMD } & \multirow{2}{*}{$\begin{array}{l}\text { CML Group } \\
N=106(\%)\end{array}$} & \multirow{2}{*}{$\begin{array}{l}\text { OG Group } \\
N=106(\%)\end{array}$} & \multirow[t]{2}{*}{$P$ value } & \multirow[t]{2}{*}{ SMD } \\
\hline & & & & & & & & & \\
\hline Age & Year & $55.5 \pm 10.7$ & $58.7 \pm 11.9$ & 0.005 & 0.288 & $55.6(10.7)$ & $55.9(13.0)$ & 0.659 & 0.021 \\
\hline \multirow[t]{2}{*}{ Sex } & Male & $72(66.1)$ & $296(67)$ & 0.946 & 0.019 & $69(65.1)$ & $68(64.1)$ & 1 & 0.020 \\
\hline & Female & $37(33.9)$ & $146(33)$ & & & $37(34.9)$ & $38(35.8)$ & & \\
\hline BMI level & $\mathrm{Kg} / \mathrm{m}^{2}$ & $22.8 \pm 3.1$ & $22.9 \pm 3.1$ & 0.733 & 0.035 & $22.7 \pm 3.1$ & $22.4 \pm 3.3$ & 0.532 & 0.117 \\
\hline \multirow[t]{2}{*}{ Tumor Size } & $<4 \mathrm{~cm}$ & $74(67.9)$ & $179(40.5)$ & $<0.001$ & 0.572 & $71(67.0)$ & $71(67.0)$ & 1 & $<0.001$ \\
\hline & $\geq 4 \mathrm{~cm}$ & $35(32.1)$ & $263(59.5)$ & & & $35(33.0)$ & $35(33.0)$ & & \\
\hline \multirow[t]{2}{*}{ Tumor Location } & AEG & $45(41.3)$ & $134(30.3$ & 0.039 & 0.230 & $42(39.6)$ & $43(40.6)$ & 1 & 0.019 \\
\hline & NonAEG & $64(58.7)$ & $308(69.7)$ & & & $64(60.4)$ & $63(59.4)$ & & \\
\hline \multirow[t]{2}{*}{ Macroscopic Type } & Type $0-2$ & $63(57.8)$ & $312(70.2)$ & 0.014 & 0.269 & $60(56.6)$ & $61(57.5)$ & 1 & 0.019 \\
\hline & Type 3-4 & $46(42.2)$ & $130(29.8)$ & & & $46(43.4)$ & $45(42.5)$ & & \\
\hline \multirow[t]{2}{*}{ Resection Type } & TG & $38(34.9)$ & $132(29.9)$ & 0.37 & 0.107 & $35(33.0)$ & $37(34.9)$ & 0.885 & 0.04 \\
\hline & DG & $71(65.1)$ & $310(70.1)$ & & & $71(67.0)$ & $69(65.1)$ & & \\
\hline \multirow[t]{5}{*}{ pT stage } & $\mathrm{T} 1$ & $46(42.2)$ & $131(29.8)$ & 0.006 & 0.406 & $46(43.4)$ & $45(42.5)$ & 0.196 & 0.301 \\
\hline & $\mathrm{T} 2$ & $20(18.3)$ & $70(15.9)$ & & & $19(17.9)$ & $16(15.1)$ & & \\
\hline & $\mathrm{T} 3$ & $31(28.4)$ & 127 (28.9) & & & $29(27.4)$ & $22(20.8)$ & & \\
\hline & $\mathrm{T} 4$ & $12(11.0)$ & $111(25.3)$ & & & $12(11.3)$ & $23(21.7)$ & & \\
\hline & $\mathrm{AGC}$ & $63(57.8)$ & $308(70.2)$ & 0.018 & 0.260 & $60(56.6)$ & $61(57.5)$ & 1 & 0.019 \\
\hline \multirow[t]{5}{*}{ pN stage } & No & $52(47.7)$ & $172(38.9)$ & 0.004 & 0.424 & $51(48.1)$ & $56(52.8)$ & 0.526 & 0.206 \\
\hline & N1 & $24(22.0)$ & $66(14.9)$ & & & $23(21.7)$ & $15(14.2)$ & & \\
\hline & $\mathrm{N} 2$ & $20(18.3)$ & $81(18.3)$ & & & $19(17.9)$ & $19(17.9)$ & & \\
\hline & N3 & 13 (11.9) & $123(27.8)$ & & & $13(12.3)$ & $16(15.1)$ & & \\
\hline & $N(+)$ & $57(52.3)$ & $270(61.1)$ & 0.118 & 0.178 & 55 (51.9) & $50(47.2)$ & 0.583 & 0.094 \\
\hline
\end{tabular}

$C M L$ clockwise modularized laparoscopic lymphadenectomy; $O G$ open gastrectomy; $S M D$ standardized mean difference; $A E G$ adenocarcinoma of esophagogastric junction; $T G$ total gastrectomy; $D G$ distal gastrectomy

Fig. 5 Standardized differences and distribution of baseline clinicopathological characteristics before and after propensity score matching. Age (Years); Sex (Male, Female); Tumor Size $(<4 \mathrm{~cm}$ and $\geq 4 \mathrm{~cm})$; Tumor Location (adenocarcinoma of esophagogastric junction and Nonadenocarcinoma of esophagogastric junction; Macroscopic Type (Type 0-2 and Type 3-4); Resection Type (Distal gastrectomy and Total gastrectomy); T stage (T1 and $\mathrm{T} 2-\mathrm{T} 4$ ), and $\mathrm{N}$ stage ( $\mathrm{N} 0$ and N1-3)

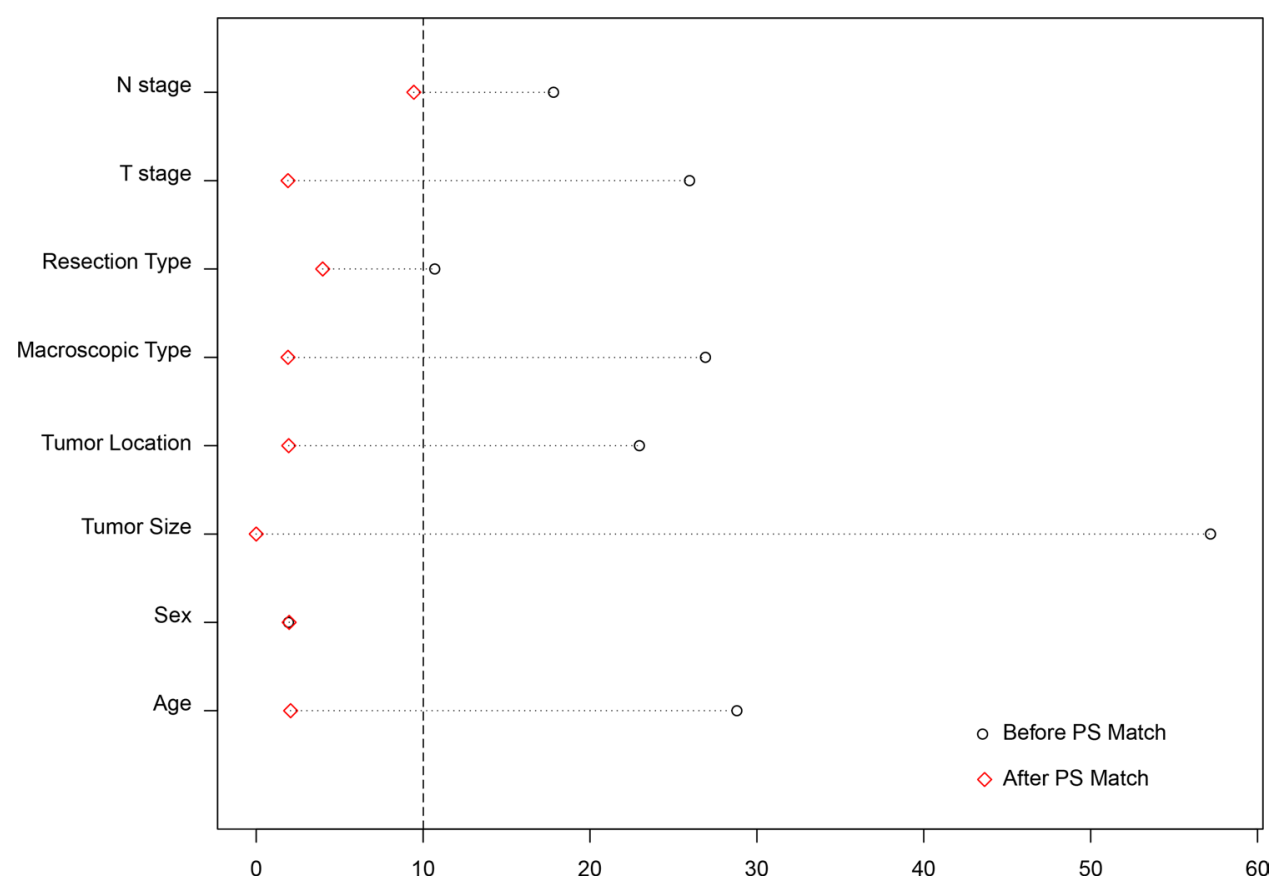


Table 2 The clinical outcomes between the clockwise modularized laparoscopic group and open gastrectomy group

\begin{tabular}{|c|c|c|c|c|c|c|c|}
\hline \multirow[t]{3}{*}{ Characteristics } & & \multicolumn{3}{|c|}{ Before Matching $(N=551)$} & \multicolumn{3}{|c|}{ After Matching $(N=212)$} \\
\hline & & \multirow{2}{*}{$\begin{array}{l}\text { CML Group } \\
N=109\end{array}$} & \multirow{2}{*}{$\begin{array}{l}\text { OG Group } \\
N=442\end{array}$} & \multirow[t]{2}{*}{$P$ value } & \multirow{2}{*}{$\begin{array}{l}\text { CML Group } \\
N=106\end{array}$} & \multirow{2}{*}{$\begin{array}{l}\text { OG Group } \\
N=106\end{array}$} & \multirow[t]{2}{*}{$P$ value } \\
\hline & & & & & & & \\
\hline Operation Time & Min & $260(220-305)$ & $235(210-260)$ & $<0.001$ & $262.5(220-303.25)$ & $232(205-255)$ & $<0.001$ \\
\hline Blood Loss & $\mathrm{ml}$ & $30(20-80)$ & $80(50-100)$ & $<0.001$ & $30(20-80)$ & $80(50-100)$ & $<0.001$ \\
\hline Metastasis Lymph nodes (total) & Numbers & $1(0-3)$ & $2(0-7)$ & 0.002 & $1(0-3)$ & $0(0-3.75)$ & 0.956 \\
\hline Examined Lymph nodes (total) & Numbers & $36(28-45)$ & $29(22-37.75)$ & $<0.001$ & $36(28-44.75)$ & $29(23-39.5)$ & 0.002 \\
\hline Metastasis Lymph nodes (No.7) & Numbers & $0(0-0)$ & $0(0-0)$ & 0.034 & $0(0-0)$ & $0(0-0)$ & 0.804 \\
\hline Metastasis Lymph nodes (No.8a) & Numbers & $0(0-0)$ & $0(0-0)$ & 0.038 & $0(0-0)$ & $0(0-0)$ & 0.251 \\
\hline Metastasis Lymph nodes (No.9) & Numbers & $0(0-0)$ & $0(0-0)$ & $<0.001$ & $0(0-0)$ & $0(0-0)$ & 0.110 \\
\hline Metastasis Lymph nodes (No.11p) & Numbers & $0(0-0)$ & $0(0-0)$ & 0.048 & $0(0-0)$ & $0(0-0)$ & 0.556 \\
\hline Metastasis Lymph nodes (No.12a) & Numbers & $0(0-0)$ & $0(0-0)$ & 0.011 & $0(0-0)$ & $0(0-0)$ & 0.243 \\
\hline Examined Lymph nodes (No.7) & Numbers & $3(1-4)$ & $3(2-5)$ & 0.154 & $3(1-4)$ & $3(1.25-4)$ & 0.632 \\
\hline Examined Lymph nodes (No.8a) & Numbers & $2(1-3)$ & $1(1-2)$ & 0.028 & $2(1-3)$ & $1(1-2)$ & 0.080 \\
\hline Examined Lymph nodes (No.9) & Numbers & $3(1.5-5)$ & $2(1-3)$ & $<0.001$ & $2(1-5)$ & $2(1-3)$ & 0.007 \\
\hline Examined Lymph nodes (No.11p) & Numbers & $1(1-3)$ & $1(1-3)$ & 0.529 & $1(1-3)$ & $2(1-3)$ & 0.215 \\
\hline Examined Lymph nodes (No.12a) & Numbers & $1(0-1.5)$ & $1(1-1)$ & 0.516 & $1(0-2)$ & $1(1-1)$ & 0.844 \\
\hline
\end{tabular}

$C M L$ clockwise modularized laparoscopic lymphadenectomy; $O G$ open gastrectomy

Table 3 The postoperative 30-day complications between the clockwise modularized laparoscopic group and open gastrectomy group

\begin{tabular}{|c|c|c|c|c|c|c|c|}
\hline \multirow[t]{3}{*}{ Characteristics } & & \multicolumn{3}{|c|}{ Before Matching $(N=551)$} & \multicolumn{3}{|c|}{ After Matching $(N=212)$} \\
\hline & & \multirow{2}{*}{$\begin{array}{l}\text { CML Group } \\
N=109(\%)\end{array}$} & \multirow{2}{*}{$\begin{array}{l}\text { OG Group } \\
N=442(\%)\end{array}$} & \multirow[t]{2}{*}{$P$ value } & \multirow{2}{*}{$\begin{array}{l}\text { CML Group } \\
N=106(\%)\end{array}$} & \multirow{2}{*}{$\begin{array}{l}\text { OG Group } \\
N=106(\%)\end{array}$} & \multirow[t]{2}{*}{$P$ value } \\
\hline & & & & & & & \\
\hline Postoperative Stay & Days & $8(7-9)$ & $9(8-11)$ & $<0.001$ & $8(7-9)$ & $8(7-9)$ & 0.452 \\
\hline Postoperative Complications & Yes & $22(20.2)$ & $93(21.0)$ & 0.948 & $21(19.8)$ & $17(16.0)$ & 0.591 \\
\hline \multirow[t]{5}{*}{ Clavien-Dindo Classification } & Grade 1 & $18(81.8)$ & $81(87.1)$ & 0.474 & $18(28.6)$ & $16(94.1)$ & 0.697 \\
\hline & Grade 2 & $1(4.5)$ & $7(7.5)$ & & $1(1.6)$ & $1(5.9)$ & \\
\hline & Grade 3 & $2(9.2)$ & $3(3.2)$ & & $1(1.6)$ & $0(0.0)$ & \\
\hline & Grade 4 & $1(4.5)$ & $1(1.1)$ & & $1(1.6)$ & $0(0.0)$ & \\
\hline & Grade 5 & 0 & $1(1.1)$ & & 0 & 0 & \\
\hline \multirow[t]{8}{*}{ Details of Complications } & PPCs & $20(90.9)$ & $76(81.6)$ & & $19(17.9)$ & $16(15.1)$ & \\
\hline & Intraperitoneal Abscess & $1(4.5)$ & $2(2.2)$ & & $1(0.9)$ & 0 & \\
\hline & Anastomotic fistula & 0 & $2(2.2)$ & & 0 & 0 & \\
\hline & Gastroparesis & 0 & $5(5.4)$ & & 0 & 0 & \\
\hline & Ileus & $1(4.5)$ & $3(3.2)$ & & $1(0.9)$ & $1(0.9)$ & \\
\hline & Intraperitoneal hemorrhage & 0 & $1(1.1)$ & & 0 & 0 & \\
\hline & Upper gastrointestinal hemorrhage & 0 & $2(2.2)$ & & 0 & 0 & \\
\hline & Pancreatic fistula & 0 & $1(1.1)$ & & 0 & 0 & \\
\hline
\end{tabular}

$C M L$ clockwise modularized laparoscopic lymphadenectomy; $O G$ open gastrectomy $P P C s$ postoperative pulmonary complications

$p=0.591)$, and the Clavien-Dindo classification showed no difference between the CML and OG groups ( $p=0.697)$.

\section{Discussions}

Lymphadenectomy forms the basis of modern holistic treatment strategies for gastric cancer [20]. Laparoscopic gastrectomy presents a minimally invasive advantage over 
traditional open gastrectomy and is typically the focus of attempts to develop more advanced techniques. However, because of the limits of the abdominal space and the corresponding visual field, the technical demands for laparoscopic surgery have higher requirements for surgeons than those of open surgery. To improve the safety and efficacy of laparoscopic lymphadenectomy in gastric cancer surgery, we designed a clockwise modularized laparoscopic lymphadenectomy model based on the experience in our clinical practice [11]. This treatment strategy can examine more total lymph nodes with a shorter operation time and less intraoperative blood loss than traditional laparoscopic surgery [11]. Because of the deep anatomical location of suprapancreatic area lymph nodes, the distribution of important vessels and organs in this area, the limited abdominal space and visual field and the restricted manipulability of the tools, laparoscopic suprapancreatic lymphadenectomy is difficult, and the procedures have high technical demands. In clockwise modularized lymphadenectomy, we scheduled technical demands and skills for both the surgeons and assistants. In comparison with traditional open gastrectomy, we found that clockwise modularized lymphadenectomy can achieve a similar effect on lymph node resection in the suprapancreatic area without an increase in surgical adverse events.

Suprapancreatic lymph node dissection is one of the core elements of D2 gastrectomy [21,22]. The deep anatomical locations of the lymph nodes and tendencies of the patients to have high BMI and advanced tumor stages raise the technical difficulty of dissecting these lymph nodes [23, $24]$. In the present study, BMI $(p=0.532, \mathrm{SMD}=0.117)$ and tumor stage (pT stage, $p=0.196, \mathrm{SMD}=0.301 ; \mathrm{pN}$ stage, $p=0.526, \mathrm{SMD}=0.206$ ) were balanced by PS matching between the two study groups. Considering that the SMD of pT stage and pN stage was higher than 0.1 in the after PS match cohorts, we calculated the $p$ value and SMD between the two groups for advanced gastric cancer (T2-T4 stages, $p=1, \mathrm{SMD}=0.019$ ) and nodal positive patients $(p=0.583, \mathrm{SMD}=0.094)$. This was due to the limitations of the retrospective study, selection bias, and tumor stage differences in the selection of laparoscopic or open gastric cancer surgery. According to the recommendations from the Japanese Gastric Cancer Treatment Guidelines [16], patients who are screened for laparoscopic surgery in our center are informed of the details about the clinical tumor stage, current guidelines and clinical evidence about laparoscopic gastric cancer surgery. Then, treatment selection is decided by the patient after full communication with the surgeons. Therefore, although propensity score matching was used in the statistical analysis, because advanced stage patients prefer open surgery, the tumor stage still cannot perfectly match in the after PS match cohort.
The safety of laparoscopic gastrectomy has been proven by several previous studies for both laparoscopic distal and total gastrectomy $[6,7,25]$. We noticed that the incidence of postoperative 30-day complications was comparable between the CML and OG groups, and postoperative pulmonary complications were more common in the CML group than in the OG group (19/106 vs. 16/106). A longer surgical duration accompanied by longer anesthesia time and longerterm tracheal intubation may increase the risk of postoperative pulmonary complications [26]. Meanwhile, the severity of postoperative complications according to the ClavienDindo classification was also comparable between the two groups both before and after propensity score matching. Therefore, clockwise modularized supra-pancreas lymph node dissection does not increase the risk of postoperative complications compared with traditional open surgery. We also noticed that in the KLASS-01 and KLASS-02 studies, laparoscopic surgery had a lower incidence of postoperative complications and a shorter postoperative hospital stay [27, 28]. However, the CLASS-01 study indicated that there is no difference in postoperative complications between laparoscopic surgery and open surgery [7]. Several factors, such as tumor stage, resection pattern, anesthesia strategy and perioperative management strategy, can influence the incidence of complications and length of postoperative hospital stay. Therefore, laparoscopic surgery is at least equal to or better than open surgery in terms of short-term outcomes according to the present clinical evidence.

The number of examined lymph nodes is an important indicator for evaluating the quality of gastric cancer surgery. Currently, more than 25 examined lymph nodes is recommended for advanced gastric cancers or nodal positive cancers $[29,30]$. Higher numbers of examined lymph nodes indicate the low potential of a false-negative lymph node rate and may result in better survival outcomes [31]. Our previous study successfully demonstrated that clockwise modularized lymphadenectomy has a clinical advantage in lymph node dissection over traditional laparoscopic surgery [11]. In the present study, we found that the CML group had more total examined lymph nodes than the OG group. In the suprapancreatic area, the number of no. 9 station nodes was higher in the CML group than in the OG group. These results showed that clockwise modularized lymphadenectomy has an advantage in suprapancreatic lymph node dissection over traditional open gastrectomy.

From the aspect of operational technology and skill, the clockwise modularized method facilitates laparoscopic lymphadenectomy in the suprapancreatic area. First, the assistants make full use of the $30^{\circ}$ angle-adjusting function of the laparoscope, obtaining a visual field for overlooking the target (the suprapancreatic area) similar to that in traditional open surgery. This can reduce the risk of accidental injury to adjacent organs or tissues. In 
addition, we emphasize that the energy device must be under the view of the laparoscope and ascertain the safety of adjacent tissues. Pancreas fistula is a postoperative complication of gastric cancer surgery that can be caused not only by accidental injury from the energy device but also by direct traumatic injury from the laparoscopic forceps [32]. In the present study, the incidence of pancreatic fistula was low in both the CML group and the OG group. This is due to the advantage resulting from the adoption of the overlook view skill and the nonpressed pancreas technique during the laparoscopic operation. The overlook view skill provides a better visual field of view, and the nonpressed pancreas technique can be performed by the assistant to avoid direct injury to the pancreas from the laparoscopic instruments. In the nonpressed pancreas technique, the assistant gently pushes on the upper edge of the pancreas with the forceps instead of directly pressing deeply onto the pancreas. This technique can result in eversion of the pancreas, bringing the suprapancreatic lymph nodes closer to the laparoscope. The extorsion effect can increase the dissection space and generate better tissue tension in the gap between the splenic artery and the edge of the pancreas, which facilitates the dissection of lymph nodes along with the spleen and artery and reduces the potential of injury to these vessels. Last, the lymphadenectomy in the suprapancreatic area should be performed sequentially from individual points to surfaces and finally to the entire three-dimensional space, rather than alone in-depth in one station. For example, we first establish the left gastric vessels as the central landmark, then clear the membrane of the plica gastropancreatica from the right to left side, and finally completely removed lymphatic tissue in these areas. Subsequently, we can obtain a clearer anatomical space and view and avoid accidental injury during the operation. Therefore, the benefits of clockwise modularized suprapancreatic lymph node dissection are a similar radical degree of lymph node dissection of the suprapancreatic area, similar surgical safety, and a similar risk of postoperative complications as open surgery.

The emergence of 3-dimensional and $4 \mathrm{~K}$ laparoscope instruments can offer us stereoscopic vision and even better views of the surgical areas. Fortunately, the surgeons can continue to expand their repertoire of surgical skills, guaranteeing operational safety and benefit to the patients. Clockwise modularized laparoscopic lymphadenectomy is the result of our experience in clinical practice on gastric cancer surgery. We believe that with the continued accumulation of surgical experience, better surgical techniques and strategies will be proposed based on our present clockwise modularized model.

\section{Conclusions}

Laparoscopic lymphadenectomy for gastric cancer surgery is technically demanding. Clockwise modularized laparoscopic lymphadenectomy in the suprapancreatic area can attain similar effects without increases in postoperative adverse events as traditional open surgery.

Acknowledgements The authors also thank the substantial work of the Volunteer Team of Gastric Cancer Surgery (VOLTGA) based on the Multidisciplinary Team (MDT) of Gastrointestinal Tumors, West China Hospital, Sichuan University, China.

Funding This study was funded by 1.3.5 Project for Disciplines of Excellence, West China Hospital, Sichuan University, No. ZY2017304. Fund for Fostering Academic and Technical Leaders of Sichuan Province, No.[2017]919. Post-Doctor Research Project, West China Hospital, Sichuan University (2018HXBH010). Project funded by China Postdoctoral Science Foundation (2019M653418).

\section{Compliance with ethical standards}

Disclosures Hua Yang, Wei-Han Zhang, Kai Liu, Yu-Qing Dan, XinZu Chen, Kun Yang, Zhi-Xin Chen, Jia-Ping Chen, Zong-Guang Zhou, and Jian-Hu have no conflicts of interest or financial ties to disclose.

Open Access This article is licensed under a Creative Commons Attribution 4.0 International License, which permits use, sharing, adaptation, distribution and reproduction in any medium or format, as long as you give appropriate credit to the original author(s) and the source, provide a link to the Creative Commons licence, and indicate if changes were made. The images or other third party material in this article are included in the article's Creative Commons licence, unless indicated otherwise in a credit line to the material. If material is not included in the article's Creative Commons licence and your intended use is not permitted by statutory regulation or exceeds the permitted use, you will need to obtain permission directly from the copyright holder. To view a copy of this licence, visit http://creativecommons.org/licenses/by/4.0/.

\section{References}

1. Beyer K, Baukloh AK, Kamphues C, Seeliger H, Heidecke CD, Kreis ME, Patrzyk M (2019) Laparoscopic versus open gastrectomy for locally advanced gastric cancer: a systematic review and meta-analysis of randomized controlled studies. World J Surg Oncol 17:68

2. Kim HH, Han SU, Kim MC, Kim W, Lee HJ, Ryu SW, Cho GS, Kim CY, Yang HK, Park DJ, Song KY, Lee SI, Ryu SY, Lee JH, Hyung WJ, Korean Laparoendoscopic Gastrointestinal Surgery Study G (2019) Effect of laparoscopic distal gastrectomy vs open distal gastrectomy on long-term survival among patients with stage I gastric cancer: The KLASS-01 randomized clinical trial. JAMA Oncol 5(4):506-513. https://doi.org/10.1001/jamao ncol.2018.6727

3. Ahn SH, Kang SH, Lee Y, Min SH, Park YS, Park DJ, Kim HH (2019) Long-term survival outcomes of laparoscopic gastrectomy for advanced gastric cancer: five-year results of a phase II prospective clinical trial. J Gastric Cancer 19:102-110 
4. Inaki N, Etoh T, Ohyama T, Uchiyama K, Katada N, Koeda K, Yoshida K, Takagane A, Kojima K, Sakuramoto S, Shiraishi N, Kitano S (2015) A multi-institutional, prospective, phase II feasibility study of laparoscopy-assisted distal gastrectomy with D2 lymph node dissection for locally advanced gastric cancer (JLSSG0901). World J Surg 39:2734-2741

5. Lee HJ, Hyung WJ, Yang HK, Han SU, Park YK, An JY, Kim W, Kim HI, Kim HH, Ryu SW, Hur H, Kong SH, Cho GS, Kim JJ, Park DJ, Ryu KW, Kim YW, Kim JW, Lee JH, Kim MC, Korean Laparo-endoscopic Gastrointestinal Surgery Study G (2019) Short-term outcomes of a multicenter randomized controlled trial comparing laparoscopic distal gastrectomy with D2 lymphadenectomy to open distal gastrectomy for locally advanced gastric cancer (KLASS-02-RCT). Ann Surg 270(6):983-991. https://doi.org/10.1097/SLA.0000000000 003217

6. Yu J, Huang C, Sun Y, Su X, Cao H, Hu J, Wang K, Suo J, Tao K, He X, Wei H, Ying M, Hu W, Du X, Hu Y, Liu H, Zheng C, Li P, Xie J, Liu F, Li Z, Zhao G, Yang K, Liu C, Li H, Chen P, Ji J, Li G, Chinese Laparoscopic Gastrointestinal Surgery Study G (2019) Effect of laparoscopic vs open distal gastrectomy on 3 -year disease-free survival in patients with locally advanced gastric cancer: the CLASS-01 randomized clinical trial. JAMA 321:1983-1992

7. Hu Y, Huang C, Sun Y, Su X, Cao H, Hu J, Xue Y, Suo J, Tao K, He X, Wei H, Ying M, Hu W, Du X, Chen P, Liu H, Zheng C, Liu F, Yu J, Li Z, Zhao G, Chen X, Wang K, Li P, Xing J, Li G (2016) Morbidity and mortality of laparoscopic versus open D2 distal gastrectomy for advanced gastric cancer: a randomized controlled trial. J Clin Oncol 34:1350-1357

8. Nashimoto A, Akazawa K, Isobe Y, Miyashiro I, Katai H, Kodera Y, Tsujitani S, Seto Y, Furukawa H, Oda I, Ono H, Tanabe S, Kaminishi M (2013) Gastric cancer treated in 2002 in Japan: 2009 annual report of the JGCA nationwide registry. Gastric Cancer $16: 1-27$

9. Shu Y, Zhang W, Hou Q, Zhao L, Zhang S, Zhou J, Song X, Zhang Y, Jiang D, Chen X, Wang P, Xia X, Liao F, Yin D, Chen $X$, Zhou X, Zhang D, Yin S, Yang K, Liu J, Fu L, Zhang L, Wang Y, Zhang J, An Y, Cheng H, Zheng B, Sun H, Zhao Y, Wang Y, Xie D, Ouyang L, Wang P, Zhang W, Qiu M, Fu X, Dai L, He G, Yang H, Cheng W, Yang L, Liu B, Li W, Dong B, Zhou Z, Wei Y, Peng Y, Xu H, Hu J (2018) Prognostic significance of frequent CLDN18-ARHGAP26/6 fusion in gastric signet-ring cell cancer. Nat Commun 9:2447

10. Cancer Genome Atlas Research N (2014) Comprehensive molecular characterization of gastric adenocarcinoma. Nature 513:202-209

11. Zhang WH, Yang K, Chen XZ, Zhao Y, Liu K, Wu WW, Chen ZX, Zhou ZG, Hu JK (2019) Clockwise, modularized lymphadenectomy in laparoscopic gastric cancer surgery: a new laparoscopic surgery model. J Gastrointest Surg 23:895-903

12. Zhang WH, Chen XZ, Liu K, Chen XL, Yang K, Zhang B, Chen ZX, Chen JP, Zhou ZG, Hu JK (2014) Outcomes of surgical treatment for gastric cancer patients: 11-year experience of a Chinese high-volume hospital. Med Oncol 31:150

13. Brierley JD, Gospodarowicz MK, Wittekind C (2016) TNM classification of malignant tumours. Wiley, Hoboken

14. Japanese Gastric Cancer A (2011) Japanese classification of gastric carcinoma: 3rd English edition. Gastric Cancer 14:101-112

15. Clavien PA, Barkun J, de Oliveira ML, Vauthey JN, Dindo D, Schulick RD, de Santibanes E, Pekolj J, Slankamenac K, Bassi C, Graf R, Vonlanthen R, Padbury R, Cameron JL, Makuuchi M (2009) The Clavien-Dindo classification of surgical complications: five-year experience. Ann Surg 250:187-196
16. Japanese Gastric Cancer A (2017) Japanese gastric cancer treatment guidelines 2014 (ver. 4). Gastric Cancer: Off J Int Gastric Cancer Assoc Jpn Gastric Cancer Assoc 20:1-19

17. He H, Li H, Su X, Li Z, Yu P, Huang H, Huang C, Ye J, Li Y, Suo J, Yu J, Li G, Xu Z, Zhao G, Cao H, Hu J, Du X, Liu F, Sun Y, Chinese Laparoscopic Gastrointestinal Surgery Study G (2018) Study on safety of laparoscopic total gastrectomy for clinical stage I gastric cancer: the protocol of the CLASS02-01 multicenter randomized controlled clinical trial. BMC Cancer 18:944

18. Austin PC (2011) Optimal caliper widths for propensity-score matching when estimating differences in means and differences in proportions in observational studies. Pharm Stat 10:150-161

19. Austin PC (2009) Balance diagnostics for comparing the distribution of baseline covariates between treatment groups in propensity-score matched samples. Stat Med 28:3083-3107

20. Degiuli M, De Manzoni G, Di Leo A, D’Ugo D, Galasso E, Marrelli D, Petrioli R, Polom K, Roviello F, Santullo F, Morino M (2016) Gastric cancer: current status of lymph node dissection. World J Gastroenterol 22:2875-2893

21. Maruyama K, Gunven P, Okabayashi K, Sasako M, Kinoshita T (1989) Lymph node metastases of gastric cancer. General pattern in 1931 patients. Ann Surg 210:596-602

22. Sasako M, McCulloch P, Kinoshita T, Maruyama K (1995) New method to evaluate the therapeutic value of lymph node dissection for gastric cancer. Br J Surg 82:346-351

23. Migita K, Matsumoto S, Wakatsuki K, Ito M, Kunishige T, Nakade H, Nakatani M, Kitano M, Nakajima Y (2016) The anatomical location of the pancreas is associated with the incidence of pancreatic fistula after laparoscopic gastrectomy. Surg Endosc 30:5481-5489

24. Sato Y, Inokuchi M, Otsuki S, Fujimori Y, Kojima K (2017) Risk factor of pancreatic fistula after radical gastrectomy from the viewpoint of fatty pancreas. Dig Surg 34:455-461

25. Inokuchi $\mathrm{M}$, Otsuki $\mathrm{S}$, Ogawa $\mathrm{N}$, Tanioka $\mathrm{T}$, Okuno K, Gokita K, Kawano T, Kojima K (2016) Postoperative complications of laparoscopic total gastrectomy versus open total gastrectomy for gastric cancer in a meta-analysis of high-quality case-controlled studies. Gastroenterol Res Pract 2016:2617903

26. Hu CH, Li QL, Li HP, Fan SQ, Zhang HX, Liu XL, He Y, Huang M, Lu M, Wang SS, Wu F (2015) Rare coexistence of mediastinal hepatoid adenocarcinoma, idiopathic azoospermia and horseshoe kidney: a case report and review of the literature. Int J Clin Exp Pathol 8:11741-11746

27. Kim W, Kim HH, Han SU, Kim MC, Hyung WJ, Ryu SW, Cho GS, Kim CY, Yang HK, Park DJ, Song KY, Lee SI, Ryu SY, Lee JH, Lee HJ, Korean Laparo-endoscopic Gastrointestinal Surgery Study G (2016) Decreased morbidity of laparoscopic distal gastrectomy compared with open distal gastrectomy for stage I gastric cancer: short-term outcomes from a multicenter randomized controlled trial (KLASS-01). Ann Surg 263:28-35

28. Lee HJ, Hyung WJ, Yang HK, Han SU, Park YK, An JY, Kim W, Kim HI, Kim HH, Ryu SW, Hur H, Kong SH, Cho GS, Kim JJ, Park DJ, Ryu KW, Kim YW, Kim JW, Lee JH, Kim MC, Korean Laparo-endoscopic Gastrointestinal Surgery Study G (2019) Short-term outcomes of a multicenter randomized controlled trial comparing laparoscopic distal gastrectomy with D2 lymphadenectomy to open distal gastrectomy for locally advanced gastric cancer (KLASS-02-RCT). Ann Surg 270:983-991

29. Chen HN, Chen XZ, Zhang WH, Chen XL, Yang K, Liu JP, Zhang B, Chen ZX, Chen JP, Zhou ZG, Hu JK (2015) Necessity of harvesting at least 25 lymph nodes in patients with stage N2N3 resectable gastric cancer: a 10-year, single-institution cohort study. Medicine 94:e620

30. Zheng G, Feng F, Guo M, Xu G, Liu S, Liu Z, Sun L, Hong L, Yang J, Lian X, Fan D, Zhang H (2017) Harvest of at least 23 
lymph nodes is indispensable for stage N3 gastric cancer patients. Ann Surg Oncol 24:998-1002

31. Gonen M, Schrag D, Weiser MR (2009) Nodal staging score: a tool to assess adequate staging of node-negative colon cancer. $\mathrm{J}$ Clin Oncol 27:6166-6171

32. Matsunaga T, Saito H, Murakami Y, Kuroda H, Fukumoto Y, Osaki T (2016) Usefulness of T-shaped gauze for precise dissection of supra-pancreatic lymph nodes and for reduced postoperative pancreatic fistula in patients undergoing laparoscopic gastrectomy for gastric cancer. Yonago Acta Med 59:232-236
Publisher's Note Springer Nature remains neutral with regard to jurisdictional claims in published maps and institutional affiliations. 